\title{
Técnicas de investigación y catalogación del arte urbano desde la transdisciplinariedad: aplicaciones y retos de futuro
}

\author{
Carmen Moral Ruiz ${ }^{a}$ y Laura Luque Rodrigo ${ }^{b}$
}

âniversidad de Huelva, Avenida de las Fuerzas Armadas s/n, 21007 Huelva. maria.moral@ddi.uhu.es, ${ }^{b}$ Universidad de Jaén, Desp. 224, Edif. C5 Campus Las Lagunillas s/n, 23071 Jaén. 1luque@ujaen.es.

\begin{abstract}
Resumen
La investigación en historia del arte, exige cada vez más que se apliquen nuevos métodos, especialmente cuando se trata de arte actual con peculiaridades que lo diferencian técnica y conceptualmente de un arte más tradicional. Es el caso, por ejemplo, del arte urbano y el arte público, tanto del graffiti como de otras formas artísticas que se dan en el espacio público, ya sea por encargo o espontáneas. La propuesta metodológica pretende ser un primer paso para la conservación, investigación y difusión de las obras, basándose en la aplicación de técnicas fotogramétricas para la elaboración de un material documental tridimensional y bidimensional del arte urbano y actual que va acompañado de otros datos de registro necesarios para comprender la obra en su totalidad. Con toda esta documentación se genera información que completa la catalogación de las obras y sus posibilidades para su difusión en diversas redes. En concreto, se ha comprobado que la documentación de carácter fotogramétrico aporta información con una textura realista de carácter fotográfico, a la vez que se aportan unos datos en verdadera magnitud de la obra y el contexto tridimensional en el que se ubica o se ubicaba en el caso de haber desaparecido.
\end{abstract}

Palabras clave: arte urbano, arte público, conservación, fotogrametría, modelos tridimensionales.

\begin{abstract}
The research on Art History calls for the application of new methods, in particular for the field of art today which differs from traditional art in techniques and concept. For example, is the case of urban art and public art, graffiti and other artistic fields which are located in public spaces. Some by request and others spontaneous. The methodological proposal aims to be a first step for the conservation, research and dissemination of the works, based on the application of photogrammetric techniques for the development of a three-dimensional and two-dimensional documentary material of urban and current art that is accompanied by other necessary registration data to understand the work in its entirety. With all this data, information is generated to complete the cataloging of the works and their possibilities for dissemination in various networks. Specifically, it has been proved that photogrammetric documentation provides information with a realistic photographic texture, while providing data in true magnitude of the work and the three-dimensional context in which it is located or was located in the case of disappearance.
\end{abstract}

Keywords: urban art, public art, conservation, photogrammetry, three-dimensional models. 


\section{Introducción}

Los profesionales del patrimonio y la conservación constantemente nos enfrentamos al problema de la documentación, que entendemos que es el paso previo para la conservación del arte actual, en gran medida porque las bases de datos que manejamos no son adecuadas. La documentación y registro de obras de arte, es el paso esencial para la conservación, en ocasiones incluso el único ya que, por ejemplo, hay obras que no se podrán someter a un proceso de restauración por diversos motivos, entre los que se contempla que el propio artista considere que la degradación de la obra forma parte del proceso, cuando se trata de arte actual. Es precisamente cuando nos enfrentamos a manifestaciones artísticas recientes cuando encontramos graves problemas a la hora de catalogarlas.

Por otro lado, encontramos que las bases de datos que se manejan normalmente están pensadas bajo una concepción clásica del arte, por lo que presentan problemas a la hora de catalogar obras actuales. Éstas, generalmente, no contemplan los campos y tesauros adecuados para manifestaciones artísticas que emplean una variedad infinita de técnicas y soportes, que no siempre pueden encuadrarse en un estilo o en las que incluso resulta imposible tomar datos tan sencillos como sus dimensiones. Este problema se acrecienta cuando se trata de manifestaciones artísticas que están abocadas a una duración breve, ya sea por el hecho de ser obras que no han sido encargadas en el caso del arte urbano o por el tipo de instalación de que se trate o sencillamente por el uso de materiales orgánicos. Creemos por ello que es necesario actualizar nuestros sistemas de catalogación de arte actual, ampliando no sólo el formato de nuestras bases de datos y programas, sino aumentando la capacidad de intervención implicando a todos los sectores posibles. En este sentido, es fundamental realizar trabajos transdisciplinares donde profesionales del patrimonio de distintos ámbitos trabajemos en conjunto enriqueciendo así los estudios realizados.

\section{La catalogación del arte urbano}

Sin duda, la manera de conservar estas obras pasa al menos por su catalogación documental, sin que esto suponga un régimen de protección específico, ya que no existe legislación al respecto. Pero ¿quiénes deben de llevar a cabo esta catalogación?, y ¿cómo realizarla? Existen algunas experiencias y recomendaciones, por ejemplo, el American Institute for Conservation or Historic and Artistic Works, dedica un apartado a la conservación de los graffitis públicos, en el que da una serie de recomendaciones tanto a las instituciones que encargan dichas obras como a los autores. Elena García Gayo (2016), indica distintas maneras de preservar una obra con ejemplos, según qué es lo que se trate de salvaguardar, a las que podríamos añadir algunas más: si la idea es preservar la obra de la especulación; si la intención es que la obra permanezca en el lugar, porque es icónica; si la obra ha sido tapada, etc. Otro proyecto sobre conservación de arte contemporáneo que proponen modelos de catalogación, es el de SBMK (Foundation for the Conservation of Contemporary Art), que incluye un apartado dedicado al artista, algo que no suele contemplarse en los inventarios de bienes artísticos, pero que cuando se trata de obras de artistas vivos, es esencial, especialmente cuando es arte urbano, puesto que debe indicar si estaría dispuesto a que su obra fuera intervenida por un profesional para restaurarla o no, algo que se propuso en la ficha presentada en el Congreso YOCOCU España de 2016 (Luque y Moral, 2016). María Isabel Úbeda García, miembro del Grupo de Arte Urbano del GEIIC, publicó en Ge-Conservación, una propuesta de ficha de catalogación para arte urbano, donde se recogen numerosos campos atendiendo a criterios objetivos como son los datos técnicos y formales; criterios en base a la observación artística; criterios en base a la valoración personal; y criterios en base a la valoración extraída de la opinión o datos vertidos por el artista y/o el entorno de la obra (Úbeda, 2016). Además, Úbeda (2016) señala la importancia de trabajar en torno a la creación de un glosario de términos de uso del arte urbano.

De manera institucional, hay que señalar que el IAPH, dentro del proyecto "Patrimonio mueble urbano de Andalucía", incluyó algunos graffitis que ya se encuentran en la base de datos del Instituto (IAPH, 2019), encontrándose en la actualidad en proceso de volcado a la red. En este caso, la ficha de registro era más tradicional y no presentaba estos aspectos relativos a la opinión del autor y su posible restauración. Existen en red otros proyectos de registro de obras de arte urbano, como Google Street Art Project (2019), que tienen un total de cuatrocientas cuarenta y una obras registradas en España, que presentan una fotografía, la localización y algunos datos básicos, pero además, para algunas obras, encontramos un video con la creación de la obra. 


\section{La técnica de la fotogrametría asociada a la conservación y difusión}

El patrimonio que se encuentra vinculado de alguna forma a elementos arquitectónicos, cuenta con valores que van más allá del carácter material, incluyéndose aquellos que se relacionan con su ubicación dentro de un contexto urbano y junto con este con elementos que determinan su visibilidad. Para llevar a cabo una adecuada difusión y conservación de aquellos bienes, tales como el arte urbano y arte público, que se relacionan con estos espacios arquitectónicos, nos podemos servir de distintas técnicas entre las que se encuentra la técnica fotogramétrica a través de la que se pueden realizar levantamientos de aquellos elementos que deseamos documentar.

De forma que logremos una mejor difusión y conservación de los bienes que se pretenden documentar, debemos atender al objetivo que perseguimos para establecer la técnica adecuada a nuestros propósitos. El uso de la imagen a través del dibujo, la fotografía o la pintura ha sido desde los inicios de la Arquitectura un medio de conocimiento de la misma, y a su vez de su conservación (Almagro, 2004a). De esta forma aquellos elementos del arte urbano y el arte público, que de una manera u otra se pueden ver relacionados con elementos constructivos o de naturaleza arquitectónica, pueden ser preservados a través de levantamientos gráficos para mejorar su difusión y conservación. Nos referimos a los levantamientos gráficos para el conocimiento de la forma y la dimensión del objeto, siendo la fotogramétrica una de las técnicas para su ejecución. Por ello, este estudio trata de realizar en primera instancia una correcta documentación del bien que dé lugar a la conservación de la mayor cantidad de valores del mismo.

\subsection{Proceso de levantamiento fotogramétrico}

El uso de este tipo de técnicas fotogramétricas está motivado por las posibilidades operativas en el proceso que se puede realizar sin excesivos medios auxiliares, reducidos tiempos de trabajo de campo y un volumen amplio de información resultante (Almagro, 2003). La fotogrametría es una técnica que nos da la posibilidad de realizar la medición de cualquier objeto, ya sea mueble o inmueble, a través de una serie de procesos sobre imágenes que nos muestran el objeto en perspectiva (Almagro, 2004a). Estas imágenes en perspectiva, de las que conocemos su centro de proyección, nos aportan información sobre los puntos que en ellas se encuentran representados, que permiten, tras el proceso de cálculo, obtener las coordenadas de cada uno de estos puntos (Almagro, 2004a). Para el desarrollo de nuestras investigaciones nos ha interesado realizar un modelo con una base fotográfica, por lo que aporta a la valoración de las texturas y el aspecto superficial.

Cuando partimos de una base fotográfica contamos con una serie de ventajas que se pueden resumir en los siguientes puntos (Lerma et al., 2011): amplia información en la que se pueden variar parámetros como la escala o resolución; información de carácter métrico; posibilidad de registrar datos en 2D y 3D; información textural de los objetos; posibilidad de visualización estereoscópica; bajo coste del equipo.

Junto con las ventajas de las técnicas fotogramétricas, se deben tener en cuenta una serie de reglas en cuanto al procedimiento a seguir que fueron redactadas en el XI International Symposium of CIPA, celebrado en Sofía en 1988 que Almagro (2004b) recoge: reglas geométricas (información de control: toma de distancias entre dos puntos que se encuentren definidos y señalización de líneas verticales a través de plomadas; recubrimiento fotográfico: solape de un $50 \%$ en las imágenes, toma de fotografías a mitad de altura del objeto, inclusión de zonas externas al objeto, fotografías con una orientación diagonal a las caras y otras oblicuas solapadas con las fotografías contiguas; toma de pares estereoscópicos: evitando casos divergentes, incluyendo pares en zonas más cercanas para obtención de detalles y comprobar la cobertura estereoscópica); reglas fotográficas (geometría interna de la cámara constante: sin zoom, ni cambio de distancia de enfoque entre otras cuestiones; búsqueda de iluminación adecuada y medios auxiliares; elección de cámara con mayor grado de estabilidad y formato); reglas de organización (croquis del objeto con los datos necesarios para la toma fotográfica; formularios con el equipo utilizado y resto de datos propios del objeto patrimonial; comprobación de los datos y consideración de los errores para tomas futuras).

En esta investigación se ha utilizado el sistema fotogramétrico digital a través de la orientación de un bloque de imágenes mediante el software Photoscan $\odot$. Este software permite realizar un proceso de orientación simultánea de bloques de fotografías de forma automática, que a diferencia de aquellos que tienen cierto carácter manual, reduce el tiempo y el costo de intervención sin perjudicar la resolución y precisión de los resultados obtenidos (Fig. 1). 


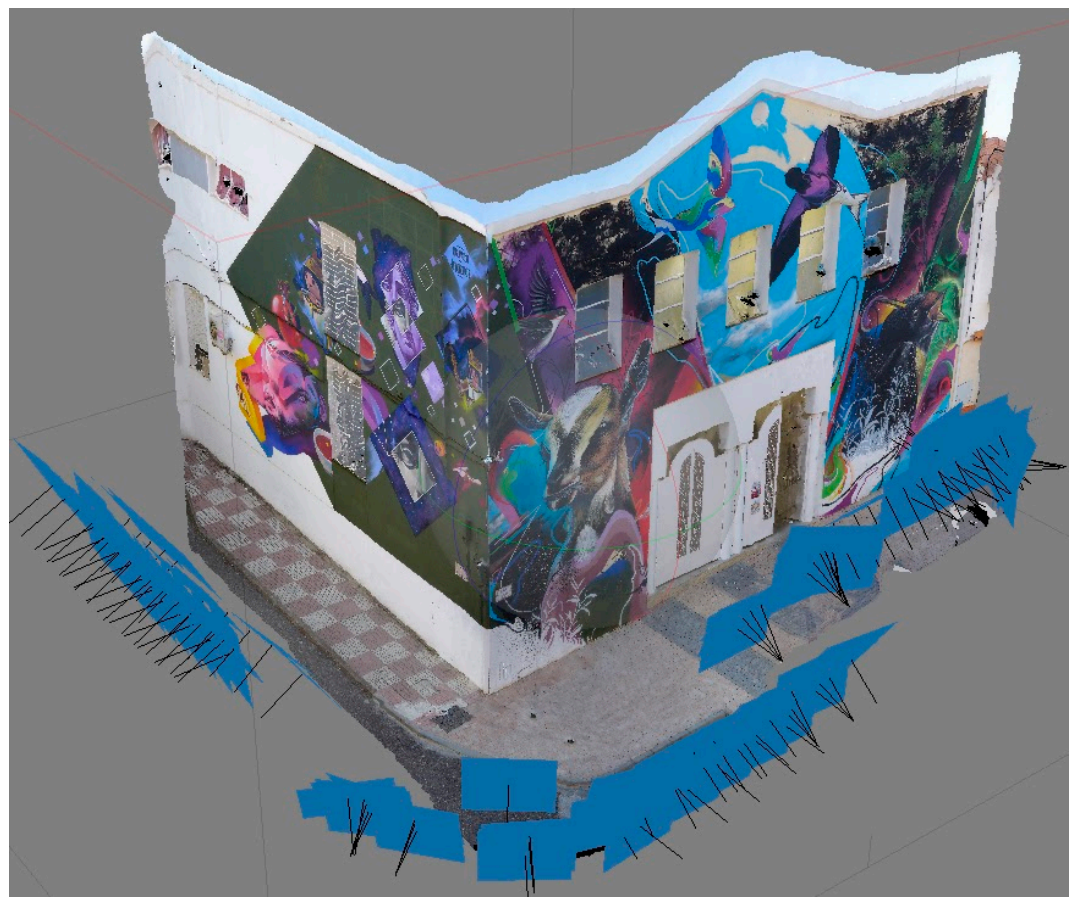

Fuente: Elaboración propia (2019)

Fig. 1 Ejemplo de recubrimiento de imágenes para proceso fotogramétrico (en azul representación de ubicación y dirección de las tomas fotográficas en Photoscan( $)$

Para poder llevar a cabo este proceso se siguen las siguientes fases principales: 1) Estudio del elemento: geometría, proporciones y detalle para conocer el número de imágenes necesarias en el barrido. 2) Estudio de accesibilidad a la zona: observar el espacio disponible y los posibles medios auxiliares necesarios, tales como trípodes. Durante el proceso de barrido fotográfico en los espacios seleccionados, en su mayoría, públicos, nos hemos encontrado las siguientes problemáticas: peatones y estorbos (vehículos, contenedores de residuos, señales de tráfico, cables, árboles, etc), geometrías complejas (ángulos de difícil acceso, con varias alturas o profundidades, rampas con varios planos en distinta orientación, etc), condiciones lumínicas múltiples (zonas de luz, en algunos casos extrema, junto con sombras arrojadas de elementos). Para este proceso de documentación fotográfica se han utilizado las siguientes cámaras: Panasonic LX7 (apertura de diafragma: variable, ISO: 100, distancia focal: 24), Nikon D3100 (apertura de diafragma: variable, ISO 100, distancia focal: 18mm), Cámara Smartphone BQ Aquarius V.

Tras la toma de imágenes se pasa a realizar el proceso fotogramétrico a través del software Photoscan@. El primer paso es la inclusión de las imágenes para su posterior alineación u orientación. Este proceso consiste en la búsqueda de puntos homólogos en cada una de ellas que luego serán utilizados para determinar las posiciones de la cámara en cada toma de imagen. A partir de estos datos se genera la nube de puntos densa. Cuando ya se han obtenido los puntos que definen el objeto se pasa a la generación de una malla de triángulos basada en la nube de puntos previa y sobre la que posteriormente se realiza un texturizado, cuyo resultado dependerá de la malla realizada y de la calidad de las imágenes tomadas (Fig. 2).
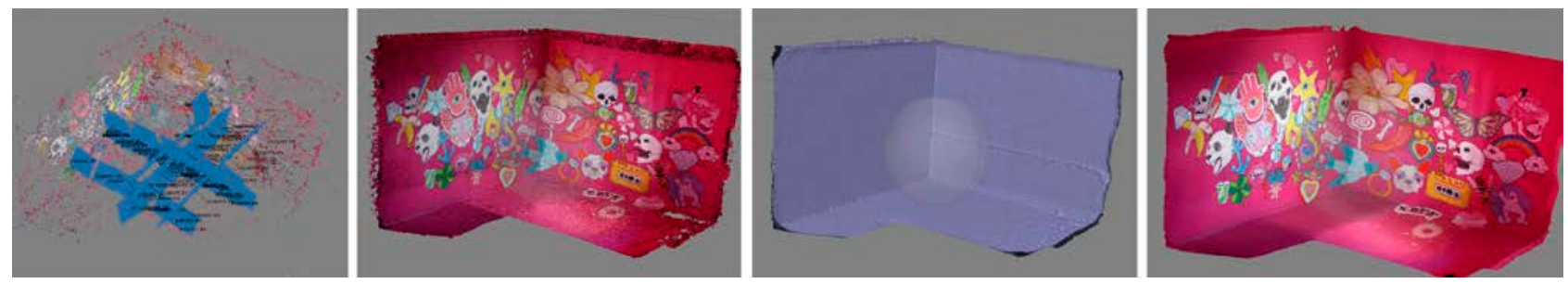

Fuente: Elaboración propia (2019)

Fig. 2 Levantamiento de obra "Llenando el vacío" (Navarro, 2018) del Festival Art Sur (La Victoria, Córdoba) a través del software Photoscan ${ }^{\circledR}$. Desde la izquierda: nube de puntos, nube de puntos densa, malla triangulada y modelo texturizado 


\subsection{Aplicaciones de la fotogrametría en arte urbano}

El concepto de arte urbano, definido por el grupo de trabajo de Arte Urbano del Grupo Español del International Institute for Conservation of Historic and Artistic Works (GE-IIC) (García et al., 2016), va mucho más allá del graffiti, recogiendo otro tipo de manifestaciones artísticas que se dan en el espacio urbano de manera espontánea, debiendo por lo tanto diferenciarse del arte público y muralismo, que serían realizados por encargo.

El alto grado de aceptación social e institucional del arte urbano ha hecho que emerjan numerosos festivales, rutas, museos, etc. Sin embargo, la correcta catalogación o inventariado de las obras es compleja por el carácter temporal de algunas, su dispersión, etc. En este sentido, la idea de este proyecto se basa en la aplicación de las técnicas fotogramétricas para la catalogación de arte urbano, es decir, incluir este apartado en fichas tipo como pudiera ser la propuesta por Úbeda (2016), ya mencionada. Para esta investigación se han elegido ejemplos de arte público mural para contar con el permiso y la aprobación para realizar la catalogación y difusión de las obras, evitando interferir en la práctica artística urbana, aunque se puede ampliar a cualquier tipo de obra de arte urbano.

\subsection{Aplicación en arte público}

Se han realizado ejemplos de documentación mediante técnicas fotogramétricas en dos ubicaciones, el Festival ArtSur en la localidad de La Victoria, en Córdoba y Murales Conciencia de Bailén, en Jaén. Estos festivales pretenden acercar el arte a un contexto rural y establecer una apropiación de los espacios públicos, permitiéndonos implementar la técnica fotogramétrica en obras muy heterogéneas: obras en esquina, obras en distintos planos, abstracción, anamorfosis, etc.

ArtSur es un festival de arte contemporáneo que comenzó a desarrollarse en La Victoria en 2014 y que se inserta dentro de Periféricos (Fundación Provincial de Artes Plásticas Rafael Botí y Diputación de Córdoba (2019). El Festival nace bajo el impulso de Sebastián Zamora Machuca y el consistorio de la localidad. Se desarrolla mediante convocatoria para artistas que presentan sus proyectos, así como para los vecinos que quieran prestar sus muros y participar en la convivencia con los artistas (Festival Art Sur, 2019). Por otro lado, Murales Conciencia (Bailén, Jaén) es un proyecto de innovación social gestionado desde Guadalinfo (2018), a través del Agente de Innovación Local Diego Ortega Alonso, con colaboración del Ayuntamiento y la Fundación Descubre (Andalucía). Desde 2017 se viene desarrollando el proyecto que pretende "crear espacios agradables y prósperos para los habitantes de la localidad y sus visitantes (Guadalinfo, 2018). En la siguiente tabla se ordenan los murales estudiados por morfologías (Tabla 1):

Tabla 1. Murales por morfología

\begin{tabular}{ll}
\hline Morfología & \multicolumn{1}{c}{ Títulos y Festival } \\
\hline Planos & La Victoria: Portugal Negro \\
& Bailén: Peces del Vivero; Simbiosis; Somos creación; La Rendición de Bailén; Stephen \\
& Hawking y la Universidad del AOVE; Cántaros Comunicantes \\
En esquina & La Victoria: Horror vacui; Inflexiones \\
Varios planos & La Victoria: Vita Intra Cete; Mantra del artista póstumo; Llenando el vacío (El dios de los tres) \\
& Bailén: Bosque de neuronas; Reforestando; Topo-Grafías; Trashöner \\
\hline
\end{tabular}

\subsection{Resultados de la aplicación de técncias fotogramétricas}

Según la selección realizada se pudieron llevar a cabo diferentes tipologías de modelos. La morfología más sencilla son aquellos modelos que se definen en un solo plano, complicándose cuando se trata de zonas de esquina o con varios planos (Fig. 3). Las mayores complicaciones en la documentación con técnicas fotogramétricas se han encontrado en modelos distribuidos en varios niveles, como el caso de rampas que además cuentan con elementos de distorsión como son las vallas de defensa (Fig. 4 Izq.). Otra de las tipologías que se han desarrollado son los modelos en interiores, que suelen tener casuísticas diversas pero sobre todo que están determinadas por los numerosos planos a registrar (techo, paredes e incluso suelo) (Fig. 4 Der.). 


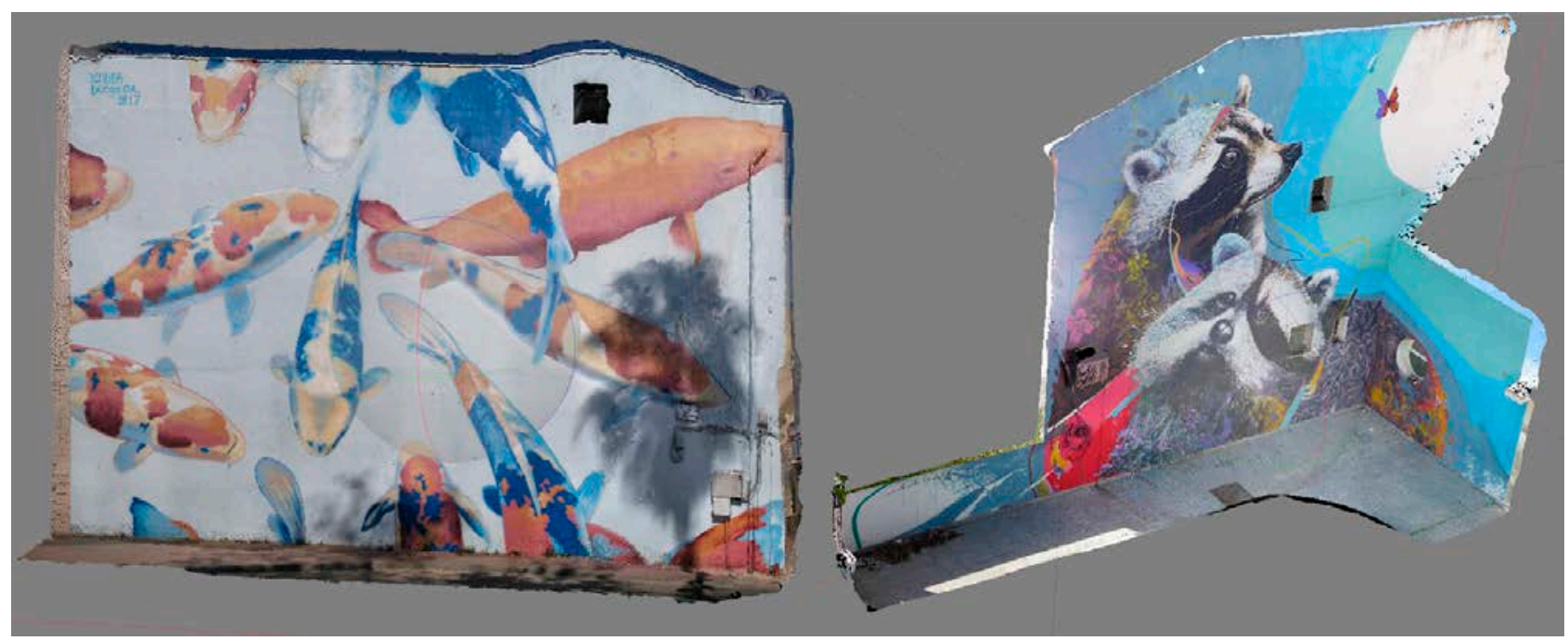

Fuente: Elaboración propia (2019)

Fig. 3 (Izq.) Modelo en un plano: Los peces del Vivero (Diego Ortega-Alonso, colabora Sendra) Murales Conciencia, Bailén. (Der.) Modelo en varios planos: Inflexiones (Kraser y Ernesto Maranje) Art Sur, La Victoria

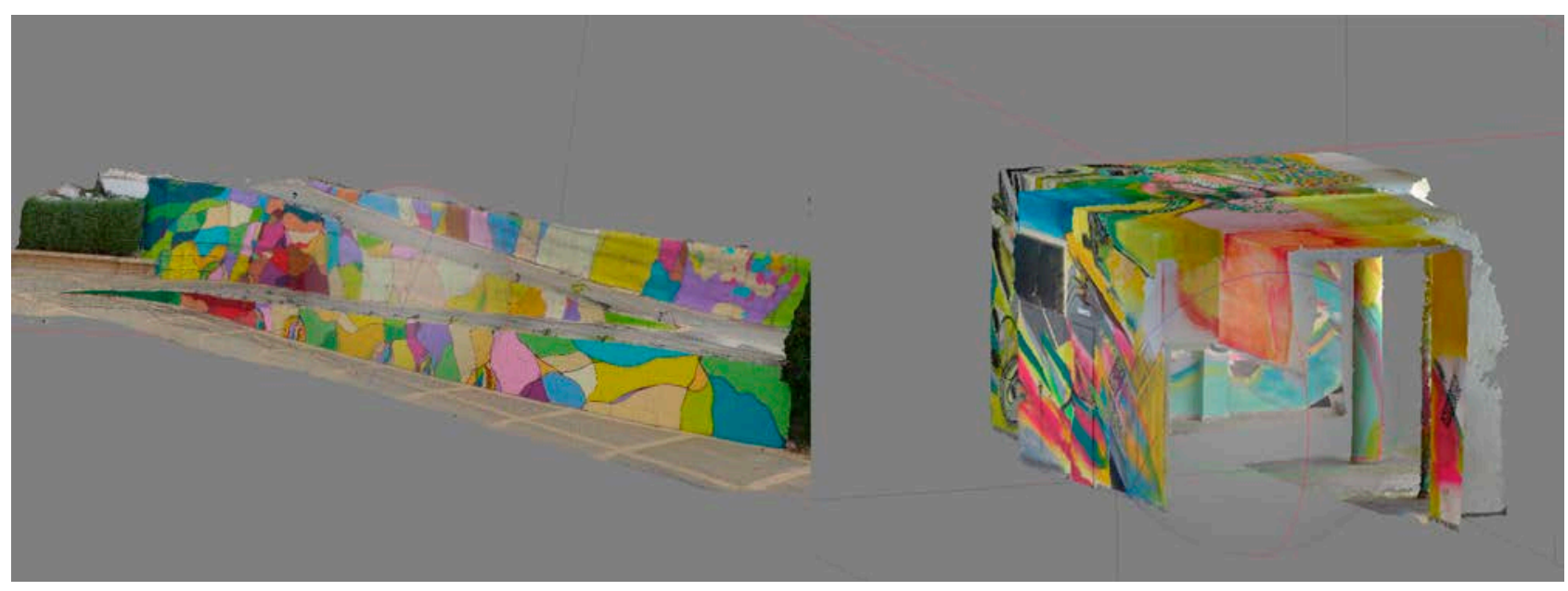

Fuente: Elaboración propia (2019)

Fig. 4 (Izq.) Modelo en varias alturas: Bosque de neuronas (Ramón Pérez Sendra) Murales Conciencia, Bailén. (Der.) Modelo en interior: Trashnöner (Paula Freire) Art Sur, La Victoria

Las problemáticas asociadas a la documentación de las obras se derivan, por un lado, a la ubicación de las obras. Debido a la presencia de elementos que distorsionan la visibilidad y complejizan enormemente la tarea de levantamiento del modelo. Al encontrarnos en un espacio público existen elementos como farolas, cubos de basura y reciclaje, jardineras, etc. que establecen puntos ciegos en las tomas fotográficas y que provocan la falta de registro de algunas zonas del modelo (Fig. 5 y 6). Por este mismo motivo derivado de la ubicación, podemos encontrarnos la presencia de sombras en los modelos debido a árboles u otro tipo de elementos, que son difíciles de evitar en determinados casos, dado que necesitamos realizar las tomas con suficiente luz, lo que conlleva la presencia de luces y sombras (Fig. 7 Der.) Por otro lado, aparecen otras problemáticas derivadas de la morfología y dimensiones de las obras a documentar, provocando que se deba realizar una mayor cantidad de fotos, ralentizando tanto el proceso en la ubicación de la obra, como el levantamiento por parte del software por la mayor cantidad de datos (Fig. 7 Izq.). 

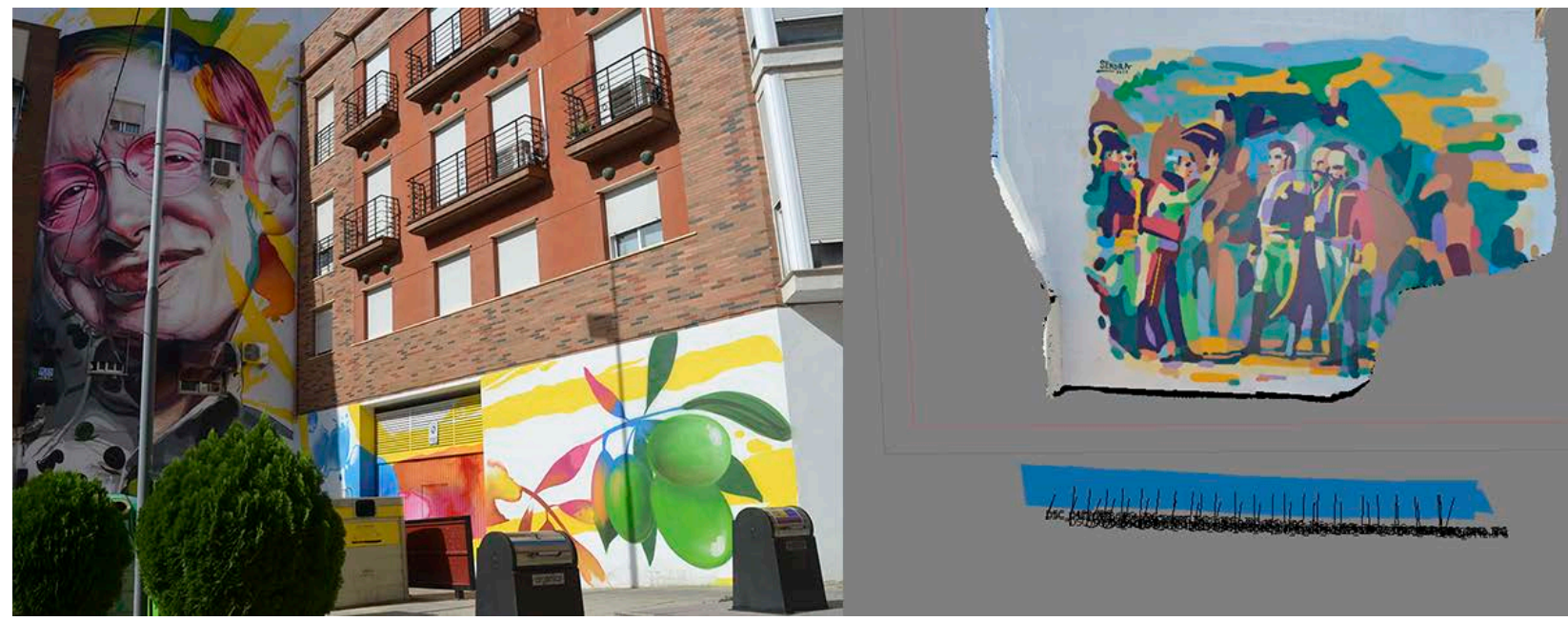

Fuente: Elaboración propia (2019)

Fig. 5 (Izq.) Elementos que entorpecen la visibilidad: Stephen Hawking y la Universidad del AOVE (Manomatic) Murales Conciencia, Bailén. (Der.) Elementos sin registrar por estorbos: Rendición de Bailén (Ramón Pérez Sendra) Murales Conciencia, Bailén

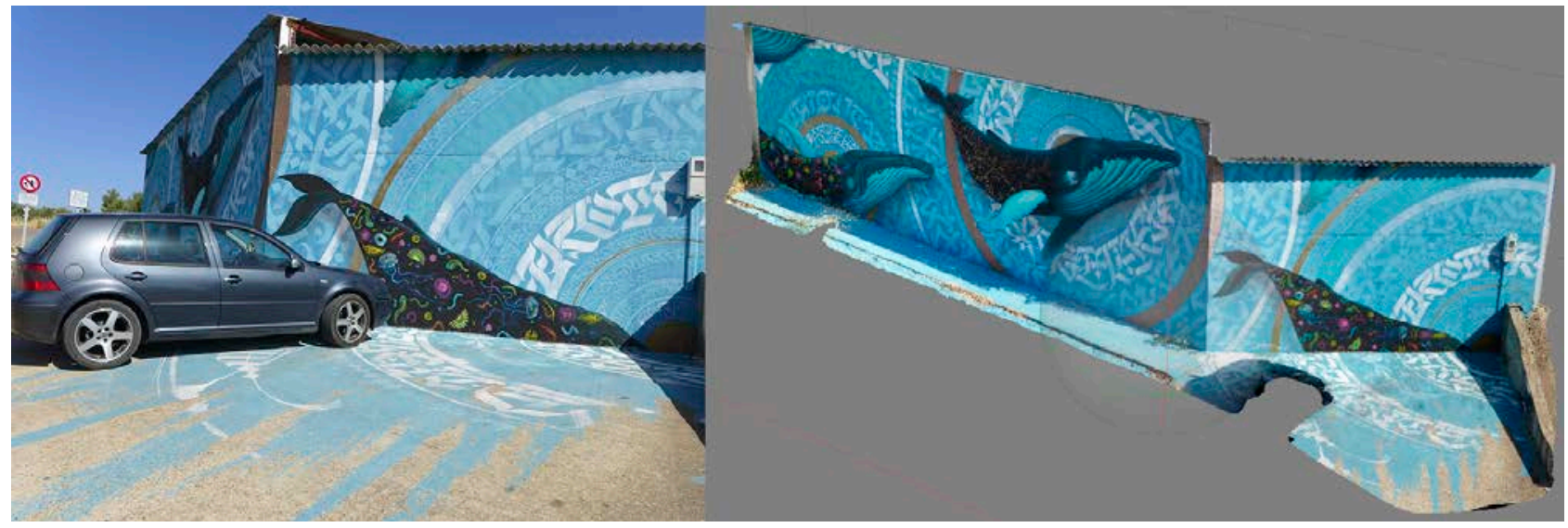

Fuente: Elaboración propia (2019)

Fig. 6 (Izq.) Elementos que entorpecen la visibilidad: Vitra Intra Cete (Peyo 0139) Art Sur, La Victoria. (Der.) Elementos sin registrar en el modelo (suelo): Vitra Intra Cete (Peyo 0139) Art Sur, La Victoria

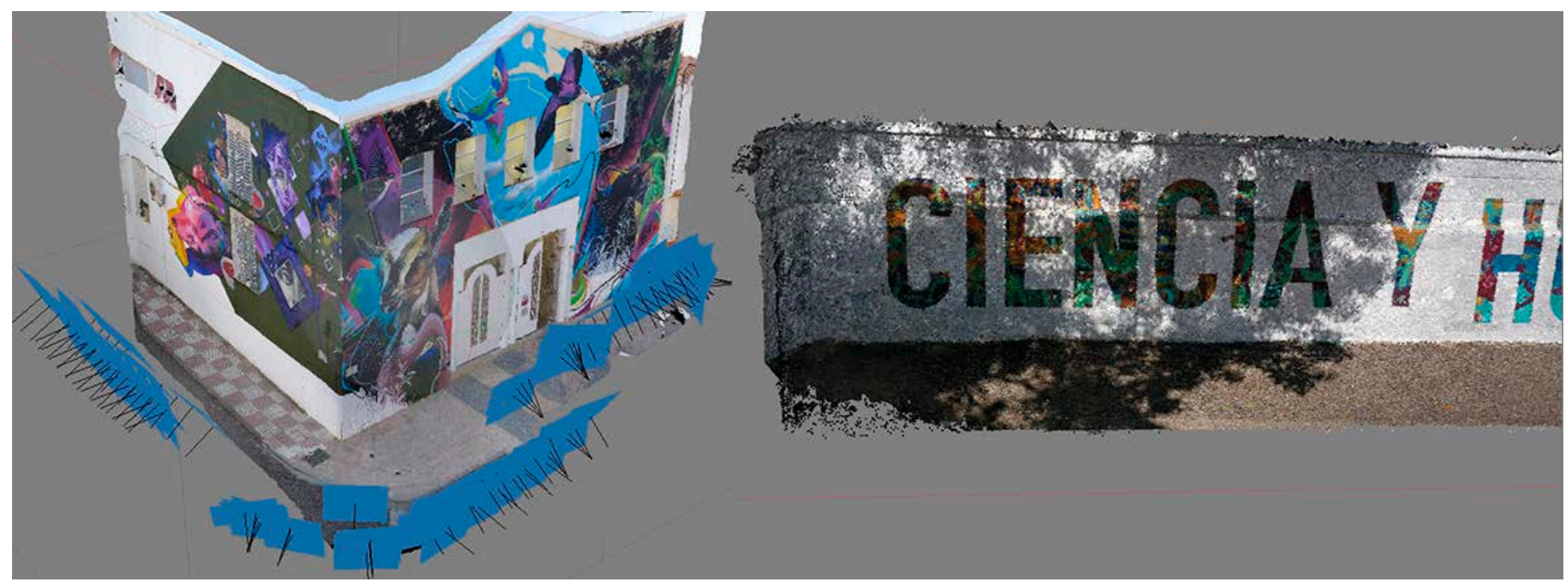

Fuente: Elaboración propia (2019)

Fig. 7 (Izq.) Dimensiones de la obra: Horror Vacui (Juan Gacedos y Mr. Trazo) Art Sur, La Victoria. (Der.) Sombras inevitables: Simbiosis (Boa Mistura) Murales Conciencia, Bailén 
En la Tabla 2 se resumen las problemáticas observadas y las posibles soluciones.

Tabla 2. Problemáticas observadas y posibles soluciones

\begin{tabular}{|c|c|c|}
\hline Problemáticas & Murales & Posibles soluciones \\
\hline $\begin{array}{l}\text { Distorsiones por múltiples } \\
\text { planos }\end{array}$ & $\begin{array}{l}\text { Trashnöner; Inflexiones; Topografías, } \\
\text { Reforestando; Llenando el vacío }\end{array}$ & $\begin{array}{l}\text { Eliminación de puntos en el modelo, } \\
\text { mayor número de tomas fotográficas. }\end{array}$ \\
\hline Vallas de defensa & Bosque de neuronas & Mayor número de tomas fotográficas. \\
\hline Sombras & Simbiosis & Cambiar horario de tomas fotográficas. \\
\hline Mala ubicación & Cántaros comunicantes & Registro parcial \\
\hline $\begin{array}{l}\text { Elementos que distorsionan la } \\
\text { visibilidad }\end{array}$ & $\begin{array}{l}\text { Vitra Intra Cete; Stephen Hawking y } \\
\text { la Universidad del AOVE; Rendición } \\
\text { de Bailén }\end{array}$ & $\begin{array}{l}\text { Mayor número de tomas fotográficas y } \\
\text { cambios de ángulo si es posible. }\end{array}$ \\
\hline Grandes dimensiones & Somos creación; Horror Vacui & Sin solución, mayor tiempo de registro. \\
\hline \multirow{2}{*}{\multicolumn{3}{|c|}{ 4. Conclusiones }} \\
\hline & & \\
\hline \multicolumn{3}{|c|}{$\begin{array}{l}\text { Se concluye que el registro mediante las técnicas fotogramétricas descritas, se concibe como necesaria y factible para } \\
\text { procurar la correcta documentación de estas obras de cara a un posterior estudio y conocimiento en el futuro, ya que, en } \\
\text { muchos casos, nos podemos enfrentar a su destrucción o deterioro. Por lo tanto, de cara a conseguir esta catalogación y } \\
\text { registro eficaz de las obras, se establece como adecuado el proceso de documentación mediante técnicas } \\
\text { fotogramétricas en cuanto a uso de recursos y tiempo, dado que esa inversión compensa el resultado y las posibilidades } \\
\text { de la información obtenida. Esto no supone que no se sea consciente de las limitaciones del proceso, ya que pueden } \\
\text { surgir levantamientos que por su complejidad no compensen el tiempo y los recursos empleados o que, a pesar de los } \\
\text { esfuerzos invertidos, no seamos capaces de registrar de forma idónea la obra. A pesar de estas excepciones, el } \\
\text { porcentaje de obras con estas problemáticas extremas son muy inferiores a las que sí se pueden registrar de forma } \\
\text { idónea. }\end{array}$} \\
\hline
\end{tabular}

\section{Referencias}

Almagro Gorbea, A. (2004a). Fotogrametría y Restitución I y II. Máster de Restauración del Patrimonio Histórico, Área 1, El conocimiento (pp. 279-301). Murcia: Universidad Politécnica de Cartagena.

Almagro Gorbea, A. (2004b). Levantamiento arquitectónico. Granada: Universidad de Granada.

Almagro Gorbea, A. (2003). Planimetría del Alcázar de Sevilla. Loggia, Arquitectura y Restauración, 14-15, 156-161.

Festival Art Sur. (2019). Festival de arte contemporáneo de La Victoria (Córdoba). La Victoria, Córdoba. Recuperado de http://www.festivalartsur.com/

Fundación provincial de artes plásticas Rafael Botí y Diputación de Córdoba. (2019). Periféricos. España. Recuperado de https://fundacionrafaelboti.com/perifericos/

Google. (2019). Street Art Google. España. Recuperado de https://streetart.withgoogle.com/es/

García Gayo, E. (2016). Etapas del Arte Urbano. Aportaciones para un Protocolo de conservación. En Ge-Conservación, 10, 186192. Recuperado de https://ge-iic.com/ojs/index.php/revista/article/view/419

García Gayo, E. et al. (2016). Anexo I: Propuesta de código deontológico para la conservación y restauración de arte urbano. GeConservación, 10, 186-192. Recuperado de https://ge-iic.com/ojs/index.php/revista/article/view/419 
Guadalinfo. (2018). El proyecto de innovación social $<<$ Murales Conciencia $>>$ de Guadalinfo Bailén (Jaén) estrena su segunda obra de arte urbano. Recuperado el 02 de noviembre de 2019, de https://blog.guadalinfo.es/el-proyecto-de-innovacion-social-muralesconciencia-de-guadalinfo-bailen-jaen-estrena-su-segunda-obra-de-arte-urbano/

IAPH. (2019). Guía digital del patrimonio Cultural de Andalucía. Andalucía, España. Recuperado de https://guiadigital.iaph.es/

Luque Rodrigo, L., y Moral Ruiz, C. (2016). Proposal for the establishment of a protocol for documentation of contemporary art. Póster presentado en la $V$ Conferencia Internacional YOCOCU 2016, Madrid, España. Recuperado de https://www.museoreinasofia.es/actividades/yococu-2016

Lerma, J. L., Cabrelles, M., Navarro, S., y Seguí, A. E. (2011). La documentación patrimonial mediante sensores de imagen o de barrido láser. En VV.AA. (2011). Documentación gráfica del Patrimonio, Actas de Jornadas sobre "Documentación Gráfica del Patrimonio Histórico. Presente y Futuro” (pp. 108-117). Madrid: Ministerio de Cultura.

Úbeda García, M. I. (2016). Propuesta de un modelo de registro para el análisis y documentación de obras de arte urbano. GeConservación, 10, 186-192. 